\title{
Cross-sectional and longitudinal associations of threat and deprivation on cognition, emotional processing and psychopathology in children and adolescents
}

Julia Luiza Schäfer ${ }^{1,2}$, Katie A. McLaughlin ${ }^{3}$, Gisele Gus Manfro ${ }^{1,2}$, Pedro Pan ${ }^{1,4}$, Luis Augusto Rohde ${ }^{1,2}$, Eurípedes Constantino Miguel ${ }^{1,5}$, Giovanni Abrahão Salum ${ }^{1,2}$

${ }^{1}$ National Institute of Developmental Psychiatry for Children and Adolescents (INCT-CNPq), São Paulo,

Brazil

${ }^{2}$ Department of Psychiatry, Universidade Federal do Rio Grande do Sul, Porto Alegre, Brazil

${ }^{3}$ Department of Psychology, Harvard University, Cambridge, United States

${ }^{4}$ Department of Psychiatry, Universidade Federal de São Paulo, São Paulo, Brazil

${ }^{5}$ Department \& Institute of Psychiatry, University of São Paulo Medical School, São Paulo, Brazil

\section{Address correspondence and reprint requests}

Julia Luiza Schäfer

Hospital de Clínicas de Porto Alegre

Ramiro Barcelos, 2350 - Porto Alegre, Brazil - 90035-003;

E-mail: julialuizaschafer@gmail.com 


\begin{abstract}
Background: Exposure to childhood adversity has been consistently associated with poor developmental outcomes, but it is unclear whether these associations vary across different forms of adversity. We examined cross-sectional and longitudinal associations between two types of adversity-threat and deprivation-with cognition, emotional processing, and psychopathology in a middle-income country.

Methods: The sample consisted of 2,511 children and adolescents (6-17 years old) from the Brazilian High-Risk Cohort for Psychiatric Disorders. Parent reports on childhood adversity were used to construct threat and deprivation latent constructs. Psychopathology was measured by the CBCL which generated a measure of general psychopathology (the "p" factor). Executive function (EF) and attention orienting toward angry faces were assessed using cognitive tasks. All measures were acquired at two time-points 3years apart. Cross-lagged panel models were estimated to evaluate longitudinal associations.

Results: Psychopathology was associated with threat and deprivation cross-sectionally, and higher levels of threat and deprivation predicted increases in general psychopathology at follow-up. For EF, worse performance was more strongly associated with deprivation than threat at baseline, and only with deprivation at follow-up. Deprivation was associated with attention orienting away from angry faces cross-sectionally, but neither form of adversity was associated with changes over time in attention bias.

Conclusion: Both types of adversity are associated with current and future psychopathology and with current, but not future, EF. Threat was more strongly linked to higher psychopathology, whereas deprivation was more strongly linked to lower EF. Lack of longitudinal associations between deprivation and EF mean reverse causality cannot be excluded.
\end{abstract}

Key words: Childhood adversity; Threat; Deprivation; Psychopathology; Executive Function; Cognition. 


\section{Introduction}

Childhood adversity involves negative environmental experiences that require considerable adaptation by an average child, including physical, emotional, and sexual abuse, neglect, domestic violence, and parental absence (McLaughlin, 2016). These experiences are highly prevalent around the world (Costello et al., 2002) and especially in low and middle income countries (Viola et al., 2016). Exposure to childhood adversity represents a public health problem due to its extensive costs to the society and individuals (Magruder, McLaughlin and Elmore Borbon, 2017), leading to poorer mental health (Green et al., 2010; McLaughlin et al., 2012) and academic achievement, such as lower grades, higher school-days absence, and more frequent suspensions (Lansford et al., 2002). Determining how distinct adverse childhood experiences influence emotional and cognitive development is critical to identify novel strategies for preventing the emergence of psychopathology and developmental problems in children who have experienced adversity.

Previous findings have suggested that different types of adverse experiences might influence development in different ways and, therefore, should be distinguished (Mclaughlin and Sheridan, 2016). One prominent model proposes that childhood adversities encompass two types of abnormal inputs (Humphreys and Zeanah, 2014): threat, the presence of an unexpected input that represents threat to the physical integrity, or well-being of the child; and deprivation, the absence of some type of expected input (McLaughlin, Sheridan and Lambert, 2014; McLaughlin, 2016). Examples of experiences involving high levels of threat are physical, sexual, and emotional abuse, witnessing domestic violence, and exposure to violence in the community, or at school; while experiences involving low levels of cognitive and social stimulation, such as neglect, institutional rearing, other forms of parental absence, and material deprivation associated with chronic poverty are characterized by high levels of deprivation (McLaughlin, Sheridan and Lambert, 2014; Sheridan and Mclaughlin, 2014; McLaughlin, 2016; McLaughlin et al., 2019).

A growing number of studies have showed that threat and deprivation influence child development differently. More specifically, children who have experienced violence, and not deprivation, require less perceptual information to identify anger (Pollak et al., 2000; Pollak and Sinha, 2002), classify a wider range of negative emotion as anger (Pollak and Kistler, 2002), and exhibit attention biases to threatening social information (Shackman and Pollak, 2014). On the other hand, exposure to deprived environments has been associated with poor performance on complex cognitive tasks, particularly those encompassing language abilities and executive function (EF) (Mclaughlin, Sheridan and Nelson, 2017; Lawson, Hook and Farah, 2018). Hence, while threat seems to have strong influences on emotional processing-particularly in relation to cues that are potentially threatening, deprivation seems to be associated with reduced performance on complex tasks reflecting EF (McLaughlin, 2016). Moreover, as it 
is of knowledge, the relationship between childhood adversity and psychopathology is already wellestablished. Although the dimensional model does not make differential predictions about how threat and deprivation influence psychopathology, emerging evidence from population-based longitudinal studies, suggests that threat may have stronger associations with psychopathology than deprivation (Platt et al., 2018).

The previous literature is limited in two important ways. First, most research using this theoretical framework has focused on youth living in high-income countries. However, most of the world's youth live in poor countries and face adversities for which there is limited data available (Viola et al., 2016). Second, most existing research investigating the associations between childhood adversity, psychopathology, and cognition is cross-sectional and does not examine how these experiences influence developmental trajectories of emotion, cognition, and psychopathology or address the possibility of bias due to reverse causality.

In this study we examined the longitudinal associations of threat and deprivation with cognition, emotion, and psychopathology in children and adolescents in a large school-based community sample from a middle-income country. Specifically, we aimed to: (1) to investigate the goodness of fit of the threat and deprivation model in a large community sample from Brazil; and (2) to investigate the associations of threat and deprivation with EF, emotional processing as measured by attention orienting toward angry faces, and psychopathology. We hypothesized that a model specifying distinctions among adversities reflecting threat and deprivation would provide a good fit to the data. We also expected that attention bias toward angry faces would be associated with threat, but not with deprivation; that worse EF would be associated with deprivation, but not with threat (McLaughlin, 2016), and that psychopathology would be associated with both threat and deprivation

\section{Methods and Materials}

\section{Study design, procedures and participants}

Data for this study is drawn from the baseline and 3-year follow-up waves of the Brazilian HighRisk Cohort for Psychiatry Disorders (BHRCS), a school-based community cohort from the cities of São Paulo and Porto Alegre. Briefly, in the year 2010, 9937 parents of 6-14-years-old children from 57 schools in São Paulo and Porto Alegre were screened using the Family History Survey (FHS; Weissman et al., 2000). From this sample, two subgroups were recruited for further assessments. One subgroup was randomly selected $(n=957)$, while the other was selected from a high-risk score procedure used to identify children with current symptoms and/or family history of psychiatric disorders $(n=1554)$. A total of 2,511 children/adolescents and their parents were assessed at two time points through questionnaires and 
interviews about the history of exposure to adversities, and psychopathology. Children/adolescents also completed neurocognitive tests at both time points. The Institutional Review Boards of all institutions involved in the study have given approval for the research protocol, and every participant, parents, or caregivers who participated has given written, or verbal informed consent. For a detailed description of the study, its procedures, and sample see Salum et al., 2014.

\section{Measures}

\section{Exposure to Adversity}

Selected variables from the BHRCS were chosen based on theoretical models of adversity. A detailed description of the selected questions and response options is depicted in the Supplemental Table S1. All baseline data was drawn considering lifetime exposure, while follow-up data was drawn considering, only, exposure over the last three years from baseline to the follow-up assessment.

Variables selected for measuring exposure to threat were drawn from two parent report sources. First, exposure to physical and sexual abuse, attack or threat, witnessing domestic violence and witnessing attack, were investigated using the Posttraumatic Stress Disorder (PTSD) assessment of the Development and Well-Being Assessment (DAWBA; Goodman et al., 2000). Second, questionnaires specifically designed for the BHRCS were used to evaluate exposure to bullying, and the frequency of exposure to psychological, physical and sexual abuse (never, once or twice, from time to time, and often) (Salum et al., 2016).

Exposure to deprivation experiences was measured through the assessment of the mother's educational level (ranging from without any study to postgraduate education), family income (measured in quintiles), socioeconomic classification (A/B - the wealthiest, $\mathrm{C}$, or $\mathrm{D} / \mathrm{E}$ - the poorest), father contact (in contact, non-contact, deceased, or unknown), and the frequency (never, once or twice, from time to time, and often) of exposure to neglect (Salum et al., 2016).

\section{Cognition}

\section{Executive Function}

Three dimensions of executive function (EF), measured by two tasks each, were calculated in order to create a second order model of EF. The dependent variable was a single EF standardized score encompassed by working memory, inhibitory control, and temporal processing scores after regressing out effects of age and gender on the task parameters. Higher scores represent better EF.

Working memory was measured by the digit span (a subtest of the WISC-III; Wechsler, 2002) and corsi blocks tasks (Vandierendonck et al., 2004). Both tasks involve the repetition of a given sequence. While in the digit span task the participants hear and repeat an increasingly difficult sequence of numbers, 
either forward and backward, in the corsi blocks task they repeat an increasingly difficult spatial sequence tapped by a researcher on up to nine identical blocks. Both outcomes are the level at which a correct repetition failed twice consecutively.

Inhibitory control was measured by the conflict control task (CCT; Hogan et al., 2005) and the go/no-go task (GNG; Bitsakou et al., 2008). Both consist of an arrow based visual stimuli with a total 100 trials divided into two different instructions. In the conflict control task, participants are asked to press a button indicating the direction or opposite direction of arrows shown on the screen. Participants either press the button indicating the correct direction of a green arrow (75 congruent trials), or press the button indicating the opposite direction of a red arrow (25 incongruent trials). The go/no-go task requires participants to completely suppress the tendency to press the buttons indicating the direction of the green arrows (75 go stimuli trials) when a double-headed green arrow (25 no-go stimuli trials) appears on the screen. For both tasks, intertrial interval was $1,500 \mathrm{~ms}$, and the stimulus duration was $100 \mathrm{~ms}$. The outcomes were the percentage of correct responses in the incongruent trials (CCT) and the percentage of failed inhibitions in the no-go trials (GNG).

Finally, temporal processing was measured by both time anticipation (TA) tasks $400 \mathrm{~ms}$ and 2,000 ms (Toplak and Tannock, 2005) on baseline, and only time anticipation $400 \mathrm{~ms}$ on the follow-up. These tasks require participants to anticipate when a visual stimulus will appear. In a game-like manner, the task involves an allied spaceship running out of oxygen and the participant has to give it to them in order to save the crew. In each task, the allied spaceship is visible for the first 10 trials, while for the remaining 16 trials the spaceship is invisible due to an invisible shield. Then, participants are asked to press a button to anticipate when it arrives. A 750-ms window of time to respond correctly and feedback after every trial are given. In task 1 , the anticipation interval is $400 \mathrm{~ms}$, while in task 2 it is $2,000 \mathrm{~ms}$. The outcome is the mean percentage of button pressed in the correct time window interval for the invisible part of the task. Tasks involving temporal delays with flexible cognitive demands have been proposed to be a part of EF in some models (Barkley, 1997). Temporal processing tasks used have previously been well-correlated with the other EF tasks in our sample (Martel et al., 2016; Manfro et al., 2019). Results for EF model fit are reported in the Supplemental Material.

\section{Emotional Processing}

Attention orienting toward angry faces

Attention orienting toward angry faces was assessed using a dot-probe task in Eprime 2.0 (Psychology Software Tools, USA). The task consists of two versions, one longer than the other, of the same identical stimuli presentation, which are paired threatening (angry) and neutral face photographs followed by a probe at the location of one of the two photographs. In both versions, each trial starts with a 
central fixation cross (for 500ms), followed by the face pair (for 500 or $1250 \mathrm{~ms}$ ) which is replaced with the probe (for $1100 \mathrm{~ms}$ ). Participants are instructed to press one of the response keys to indicate whether the probe appeared in the left, or right side of the screen. Trials are, randomly, either congruent (16 trials for the short version and 32 for the long version), with threatening faces and probes appearing on the same side of the screen, and incongruent (16 trials for the short version and 32 for the long version), with threatening faces appearing on opposite sides of the screen. The inter-trial interval varies randomly from 750 to $1250 \mathrm{~ms}$. Since the neutral and the threatening stimuli are in different screen locations, they compete for attention. Therefore, attention orienting toward angry faces is measured as the difference in reaction time between the task's trials in which the probe replaces a neutral stimulus versus those in which the probe replaces a threatening stimulus. Response times were excluded as errors from trials where the response was incorrect or did not occur before probe offset. Additionally, response times less than $200 \mathrm{~ms}$ or more than 2 standard deviation above each participant's mean were excluded as outliers, as well as attention bias scores were not calculated if more than $50 \%$ response times data were missing. Therefore, the dependent variable was a standardized score of attention orienting toward angry faces after regressing out effects of age and gender on the task parameters. Scores greater than zero represent biases in attention toward threats and lower than zero biases in attention away from threats.

\section{Psychopathology}

Psychopathology was measured dimensionally at baseline and follow-up through the Child Behavior Checklist (CBCL; Achenbach and Rescola, 2001; Bordin et al., 2013). The CBCL is a parentreport questionnaire that assesses the child's emotional, behavioral, and social problems yielding a total score (including all items), as well as an internalizing and externalizing score. A bifactor model with one dimension of general psychopathology (the "p" factor) was fitted to the data with two residualized dimensions of internalizing and externalizing psychopathology. Only general psychopathology scores were used for further analysis. More detail on the model's structure are described in the Supplemental Material.

\section{Data Analysis}

First, we conducted factor analyses in order to assess the latent structure of threat and deprivation models of exposure to adversity, as well as the EF and psychopathology models. Missing data was accounted for using full information maximum likelihood estimation. Model goodness of fit was evaluated using root-mean-square error of approximation (RMSEA), comparative fit index (CFI), and Tucker-Lewis index (TLI). According to the literature, a RMSEA equal or below .06, and a CFI and a TLI above .95 indicate good fit (Hu and Bentler, 1999; Kline, 2013). Second, we used the observed factor 
scores from the validated models to test the longitudinal associations of threat and deprivation with psychopathology, cognition, and emotional processing through Cross-Lagged Panel Models (CLPM) with baseline and 3-year follow-up assessments. Given that EF was comprised of multiple distinct tasks, we additionally examined associations of threat and deprivation with each of the three components of EF. Such analysis was chosen to investigate longitudinal associations due to CLPM estimation of the directional influence variables have over time, while controlling for correlations within time-points and autoregressive effects (or stability) across time, which provide a robust strategy for estimating longitudinal associations and minimizing bias due to reverse causality (Kearney, 2018). Data analysis were performed using the Mplus software for categorical data and the lavaan package from $\mathrm{R}$ for continuous data and CLPMs.

\section{Results}

\section{Descriptive Statistics}

The total sample was comprised of 2,511 children and adolescents with a mean age of 10.42 years old at baseline and 13.71 years old on follow-up. Among those, 1375 (54.8\%) were female, and 1256 (50.1\%) were from the city of São Paulo. Descriptive data on variables of interest are shown on Table 1 and additional descriptive data is found in the Supplemental Material.

\section{Threat and Deprivation Latent Structure}

The model of threat and deprivation as latent variables (Supplemental Figure S1) was tested at both the baseline and follow-up assessments. The baseline model, consisting of nine variables informing the threat dimension and five variables informing the deprivation dimension, showed acceptable fit indexes $(\mathrm{CFI}=0.942$, TLI $=0.928, \mathrm{RMSEA}=0.036)$. For the follow-up model, frequency of exposure was considered for the three-year time frame between baseline and follow-up assessments. Due to low frequency on both variables assessing sexual abuse exposure over the last three years, these variables were combined. Therefore, the follow-up model consisted of eight variables informing the threat dimension and five variables informing the deprivation dimension, presenting acceptable goodness of fit $(\mathrm{CFI}=0.923, \mathrm{TLI}=0.903, \mathrm{RMSEA}=0.037)$. Detailed information is provided on Table 2.

\section{Cross-sectional and cross-lagged effects from the Cross-Lagged Panel Models}

The analysis investigating effects of threat and deprivation and psychopathology, EF and attention orienting toward angry faces from the CLMP are depicted in Table 3 and summarized below. 


\section{Executive Function}

Executive function was moderately stable over the course of development $(\beta=0.435, p<0.001)$. Cross-sectional analysis showed worse EF performance was more strongly associated with deprivation $(\beta=-0.155, \mathrm{p}<0.001)$ than threat $(\beta=-0.086, \mathrm{p}<0.001)$ at baseline and executive function was only associated with deprivation at follow-up $(\beta=-0.061, \mathrm{p}=0.008)$. Longitudinal analysis showed no significant effects of either threat or deprivation on change in executive function over the three-year follow-up (Figure 1 - Panel B).

Post hoc analyses were conducted in order to investigate the impact of adversity on specific dimensions of EF and are shown on Table 4. All dimensions of EF were stable over the course of three years (WM, $\beta=0.432, p<0.001 ; \mathrm{IC}, \beta=0.310, \mathrm{p}<0.001$; TP, $\beta=0.296, \mathrm{p}=0.025$ ). Cross-sectional results indicate that threat was associated with worse performance in working memory $(\beta=-0.079, \mathrm{p}<0.001)$ and temporal processing tasks $(\beta=-0.082, \mathrm{p}<0.001)$ at baseline, but not follow up. Also, deprivation was associated with all three dimensions (working memory, inhibitory control and temporal processing) of executive function at baseline (WM, $\beta=-0.146, \mathrm{p}<0.001 ; \mathrm{IC}, \beta=-0.052, \mathrm{p}<0.001 ; \mathrm{TP}, \beta=-0.154$, $\mathrm{p}=0.025)$, and working memory $(\beta=-0.057, \mathrm{p}=0.014)$ and inhibitory control $(\beta=-0.067, \mathrm{p}=0.004)$ at follow up. Longitudinal results indicate that deprivation, and not threat, at baseline predicted worsening performance on inhibitory control tasks over time $(\beta=-0.086, \mathrm{p}<0.001)$, but no other dimension of EF.

\section{Attention orienting toward angry faces}

Biases toward angry faces at follow-up was significantly predicted by baseline levels, even though it was less stable than EF and general psychopathology $(\beta=0.064, p=0.025)$. Cross-sectional analysis showed deprivation was associated with bias away from angry faces at follow-up ( $\beta=-0.057$, $\mathrm{p}=0.024$,), but longitudinal analysis did not reveal any significant associations (Figure 1 - Panel C).

General psychopathology (the "p" factor)

General psychopathology was moderately stable over the course of three years $(\beta=0.336$, $\mathrm{p}<0.001)$. Cross-sectional analysis revealed psychopathology was more strongly associated with threat than with deprivation at both baseline (Threat, $\beta=0.430, \mathrm{p}<0.001$; Deprivation, $\beta=0.160, \mathrm{p}<0.001$ ) and follow-up (Threat, $\beta=0.349$, $p<0.001$; Deprivation, $\beta=0.058, p=0.010$ ). Longitudinal predictions showed that both, threat $(\beta=0.121, \mathrm{p}<0.001)$ and deprivation $(\beta=0.064, \mathrm{p}=0.003)$, predicted increases in general psychopathology three years later (Figure 1 - Panel A).

Bidirectional effects 
Despite not being part of our primary hypothesis, our CLPM detected some bidirectional associations. We found that higher general psychopathology at baseline predicted future exposure to both threat and deprivation. Similarly, worse EF performance at baseline modestly predicted higher levels of exposure to deprivation three years later.

\section{Discussion}

This study examined theoretical predictions of a dimensional model of childhood adversity (McLaughlin et al., 2014). Specifically, we evaluated the associations of threat and deprivation assessed dimensionally and modeled as latent factors with $\mathrm{EF}$, attention orienting to threat, and psychopathology over time using a large sample in a middle-income country.

In accordance to previous findings, our results also suggest that threat and deprivation have differential associations with cognitive and emotional development, as well as psychopathology, even though not all hypotheses were supported. In particular, threat was more strongly associated with psychopathology than deprivation, and deprivation more strongly associated with EF than threat. However, threat was not uniquely associated with attention bias towards threat as expected, and instead deprivation was associated with attention bias away from threat. This pattern of findings has theoretical implications for conceptual models of adversity and development, as well as clinical implications regarding potential targets for early interventions aimed at preventing the long-term consequences of adversity for mental health and academic achievement.

There is mounting evidence showing that childhood adversity is associated with high levels of general psychopathology, both cross-sectionally and prospectively (Green et al., 2010; Dunn et al., 2017; McLaughlin et al., 2012). This link tends to span all forms of psychopathology, including both internalizing and externalizing domains (Salum et al., 2016) - and therefore associations with general expressive indexes of psychopathology (such as the "p" factor) are expected (Miller et al., 2016), as we confirmed here. Also, in line with some previous evidence and theoretical models (Busso, McLaughlin and Sheridan, 2017), we showed associations between adversity and psychopathology were revealed for both types of adversity domains. However, the associations of with psychopathology were stronger for threat than deprivation, which might reveal a more prominent role of the threat domain on shared expression of psychopathology, as already noted by direct and indirect effects of threat and deprivation, respectively, on psychopathology (Miller et al., 2016; Platt et al., 2018).

Although both threat and deprivation were each associated with worse performance on EF tasks at baseline, the associations were stronger for deprivation when compared to threat, and only deprivation predicted changes in EF over the follow-up period. This pattern is consistent with previous cross-sectional 
studies that observing that experiences characterized by deprivation, and not threat, are related to deficits in EF (Bos, 2009; Beckett et al., 2010; Sheridan et al., 2017; Machlin et al., 2019; Lambert et al., 2017). In contrast to our hypotheses, neither threat nor deprivation predicted overall changes in general EF over time. However, post hoc analyses showed that deprivation predicted worsening performance on inhibitory control tasks over time. This suggests that different adversity types may differentially influence the development of specific domains of $\mathrm{EF}$, consistent with prior work suggesting that specific types of adversity exposure might differentially impact specific cognitive abilities (Noble, McCandliss and Farah, 2007; Lambert et al., 2017), and that cognitive control might be a domain of particular relevance for children who have experienced deprivation. These findings are broadly consistent with theoretical predictions arguing that deprivation may uniquely influence the development of EF in children and adolescents (McLaughlin et al., 2014; Sheridan \& McLaughlin, 2014).

Different from what was expected, no associations were found between both dimensions of childhood adversity exposure and attention orienting toward angry faces. Conversely, a slight crosssectional association between deprivation and attention orienting away from angry faces was found at follow-up. Even though previous research has already shown that children and adolescents exposed to different forms of adversity present higher attention bias toward angry faces when compared to those not exposed (Pollak and Tolley-Schell, 2003; Briggs-Gowan et al., 2015; Miller, 2015), this association might depend on the developmental period of assessment. Attention bias toward threat tend to decrease from childhood through adolescence (Reinholdt-Dunne et al., 2012), suggesting that with the coming of age the ability to deliberately direct attention away from threat might increase. Supporting that notion and the association between deprivation and attention bias away from threat found at follow up, the association between exposure to adversity and attention bias away from threat among adolescents, and not children, has already been documented (Weissman et al., 2019). Such results should be interpreted with caution due to the low stability of the attention bias measure in this study, considering that the utility of using the dot-probe has already been called into question due to its low-retest reliability (Chapman, Devue and Grimshaw, 2019).

Our study has a number of strengths. First, by using a dimensional approach to childhood adversities, we were able to distinguish possible differential impacts of distinct experiences on psychopathology, EF, and attention orienting toward angry faces supporting evidence of the pathways through which adversity impacts child development. Second, our longitudinal design allowed us to explore the associations of threat and deprivation with developmental change in these domains over time, which has rarely been done in existing studies of adversity dimensions. Some limitations also should be 
noted. First, our study used a school-based sample assessed mainly with parent-reported events. Childreported information would be an important piece of information to be investigated in future studies. Second, literature suggests that the deprivation dimension is characterized by cognitive stimulation, or an enriched cognitive environment (Sheridan and Mclaughlin, 2014). Our deprivation dimension did not account for any of those specific variables, suggesting that we might not be capturing deprivation as a whole. Third, attention orienting toward angry faces might captures only one relatively constrained domain of emotional processing. Because no other measure of emotional information processing was assessed in this study, we were not able to capture the effects of adversity on other domains of emotional processing argued to be particularly likely to be influenced by threat-related adversity, including emotional reactivity, emotional learning, and emotion regulation (McLaughlin \& Lambert, 2017).

Exposure to adversity, especially during childhood, is a complex phenomena with meaningful and well-established effects on child development. Because adversity can take upon many forms, dimensional models - as the one investigated here-might help to disentangle the specific developmental impacts of different forms of exposure. This knowledge facilitates the identification of the risks conferred to certain individuals when exposed to certain types of adversity, as well as which interventions could be more effective in buffering these negative impacts on development. Bidirectional results suggest that reverse causality cannot be excluded, but they should be interpreted with caution given the lack of a genetically sensitive design. Therefore, further investigations on bidirectional longitudinal relationships among the variables using genetic informed models and on possible moderators and mediators for the relationships found in this paper seem to be a promising direction. Such investigations could generate more information in order to more effectively support healthy and adaptive child development through targeted interventions to high-risk populations. 


\section{Acknowledgements}

The authors thank the children and families from the Brazilian High-Risk Cohort for Psychiatric Disorders, as well as all the researchers and staff for making this study possible.

\section{Funding}

The Brazilian High-Risk Cohort for Psychiatric Disorders is supported by the National Institute of Developmental Psychiatry for Children and Adolescents, through research grants from the Conselho Nacional de Desenvolvimento Científico e Tecnológico (CNPq, Brazil; grant numbers 73974/2008-0, 465550/2014-2); the Coordenação de Aperfeiçoamento de Pessoal de Nivel Superior (CAPES, Brazil); the Fundação de Amparo à pesquisa do Estado de São Paulo (FAPESP, Brazil; grant numbers 2008/57896-8, 2014/50917-0); and the Fundação de Amparo à Pesquisa do Estado do Rio Grande do Sul (FAPERGS, Brazil).

\section{Conflict of Interest}

Dr. Pan has received payment for the development of educational material for AstraZeneca and JanssenCilag. Dr. Rohde has served on speakers bureaus, on advisory boards, or as a consultant for Eli Lilly, Janssen-Cilag, Medice, Novartis, and Shire; he receives royalties from Oxford University Press and ArtMed; the ADHD and Pediatric Bipolar Disorder Outpatient Programs chaired by him have received unrestricted educational and research support from Eli Lilly, Janssen-Cilag, Novartis, and Shire; and he has received travel grants from Shire and Novartis to attend annual association meetings. Dr. Manfro and Dr. Salum received research grants from the national funding agencies FAPERGS, CAPES and CNPq. Dr. Miguel received research grants from the national funding agencies CAPES, CNPq and FAPESP. The other. authors no conflict interests which impact this work.

\section{Ethical Standards}

The authors assert that all procedures contributing to this work comply with the ethical standards of the relevant national and institutional committees on human experimentation and with the Helsinki Declaration of 1975, as revised in 2008. 


\section{References}

Achenbach, T. M. and Rescola, L. A. (2001) Manual for the ASEBA school-age forms \& profiles. Burlington.

Barkley, R. A. (1997) 'Behavioral inhibition, sustained attention, and executive functions: Constructing a unifying theory of ADHD', Psychological Bulletin, 121(1), pp. 65-94. doi: 10.1037/0033-2909.121.1.65.

Beckett, C. et al. (2010) 'Institutional deprivation, specific cognitive functions, and scholastic achievement: English and Romanian Adoptee (Era) study findings', Monographs of the Society for Research in Child Development, 75(1), pp. 125-142. doi: 10.1111/j.1540-5834.2010.00553.x.

Bitsakou, P. et al. (2008) 'Inhibitory deficits in attention-deficit/hyperactivity disorder are independent of basic processing efficiency and IQ', Journal of Neural Transmission, 115(2), pp. 261-268. doi: 10.1007/s00702-007-0828-z.

Bordin, Isabel A et al. (2013) 'Child Behavior Checklist (CBCL), Youth Self- Report (YSR) and Teacher's Report Form (TRF): an overview of the development of the original and Brazilian versions', Cadernos de Saúde Pública, 29(1), pp. 13-28. doi: 10.1590/S0102-311X2013000500004.

Bos, K. J. (2009) 'Effects of early psychosocial deprivation on the development of memory and executive function', Frontiers in Behavioral Neuroscience, 3(September), pp. 1-7. doi: 10.3389/neuro.08.016.2009.

Briggs-Gowan, M. J. et al. (2015) 'Attention bias and anxiety in young children exposed to family violence', Journal of Child Psychology and Psychiatry, 56(11), pp. 1194-1201.

Busso, D. S., McLaughlin, K. A. and Sheridan, M. A. (2017) 'Dimensions of Adversity, Physiological Reactivity, and Externalizing Psychopathology in Adolescence: Deprivation and Threat', Psychosomatic Medicine, 79(2), pp. 162-171. doi: 10.1097/PSY.0000000000000369.

Chapman, A., Devue, C. and Grimshaw, G. M. (2019) 'Fleeting reliability in the dot-probe task', Psychological Research. Springer Berlin Heidelberg, 83(2), pp. 308-320. doi: 10.1007/s00426-017-09476.

Costello, E. J. et al. (2002) 'The Prevalence of Potentially Traumatic Events in Childhood and Adolescence', 15(2), pp. 99-112.

Dunn, E. C. et al. (2017) 'Sensitive periods for the effect of childhood interpersonal violence on psychiatric disorder onset among adolescents', British Journal of Psychiatry, 211(6), pp. 365-372. doi: 10.1192/bjp.bp.117.208397.

Goodman, R. et al. (2000) 'The Development and Well-Being Assessment: Description and initial validation of an integrated assessement of child and adolescent psychopathology', Journal of Child Psychology and Psychiatry and Allied Disciplines, 41(5), pp. 645-655. doi: 10.1017/S0021963099005909.

Green, J. G. et al. (2010) 'Childhood adversity and adult psychopathology in the National Comorbidity Survey Replication (NCS-R)-I: Associations with first onset of DSM-IV disorders', Archives of General Psychiatry, 67(2), pp. 1-21. doi: 10.1001/archgenpsychiatry.2009.186.Childhood.

Hogan, A. M. et al. (2005) 'Maturation of action monitoring from adolescence to adulthood: An ERP study', Developmental Science, 8(6), pp. 525-534. doi: 10.1111/j.1467-7687.2005.00444.x. 
Hu, L. T. and Bentler, P. M. (1999) 'Cutoff criteria for fit indexes in covariance structure analysis: Conventional criteria versus new alternatives', Structural equation modeling: a multidisciplinary journal, 6(1), pp. 1-55.

Humphreys, K. L. and Zeanah, C. H. (2014) 'Deviations from the Expectable Environment in Early Childhood and Emerging Psychopathology', Neuropsychopharmacology. Nature Publishing Group, 40(1), pp. 153-169. doi: 10.1038/npp.2014.165.

Kearney, M. W. (2018) 'Cross-Lagged Panel Analysis', The SAGE Encyclopedia of Communication Research Methods, pp. 313-314. doi: 10.4135/9781483381411.n117.

Kline, R. B. (2013) 'Exploratory and confirmatory factor analysis', in Petscher, Y. and Schatsschneider, C. (eds) Applied quantitative analysis in the social sciences. New York: Routledge, pp. 171-207.

Lambert, H. K. et al. (2017) 'Differential associations of threat and deprivation with emotion regulation and cognitive control in adolescence', Development and Psychopathology, 29(3), pp. 929-940. doi: $10.1017 /$ S0954579416000584.

Lansford, J. E. et al. (2002) 'A 12-year prospective study of the long-term effects of early child physical maltreatment on psychological, behavioral, and academic problems in adolescence', Archives of Pediatrics and Adolescent Medicine, 156(8), pp. 824-830. doi: 10.1001/archpedi.156.8.824.

Lawson, G. M., Hook, C. J. and Farah, M. J. (2018) 'A meta-analysis of the relationship between socioeconomic status and executive function performance among children Gwendolyn', Developmental Science, 21(2). doi: 10.1111/desc.12529.

Machlin, L. et al. (2019) 'Differential Associations of Deprivation and Threat With Cognitive Control and Fear Conditioning in Early Childhood', Frontiers in Behavioral Neuroscience, 13(May), pp. 1-14. doi: 10.3389/fnbeh.2019.00080.

Magruder, K. M., McLaughlin, K. A. and Elmore Borbon, D. L. (2017) 'Trauma is a public health issue', European Journal of Psychotraumatology. Taylor \& Francis, 8(1), p. 1375338. doi: 10.1080/20008198.2017.1375338.

Manfro, A. G. et al. (2019) 'Heterotypic trajectories of dimensional psychopathology across the lifespan: the case of youth-onset attention deficit/hyperactivity disorder', Journal of Child Psychology and Psychiatry and Allied Disciplines, 60(5), pp. 533-544. doi: 10.1111/jcpp.12987.

Martel, M. M. et al. (2016) 'A General Psychopathology Factor ( P Factor ) in Children $\square$ : Structural Model Analysis and External Validation Through Familial Risk and Child Global Executive Function', Journal of Abnormal Psychology.

Mclaughlin, K. A. et al. (2012) 'Childhood Adversities and First Onset of Psychiatric Disorders in a National Sample of US Adolescents', 69(11), pp. 1151-1160.

McLaughlin, K. A. (2016) 'Future Directions in Childhood Adversity and Youth Psychopathology', Journal of Clinical Child and Adolescent Psychology, 45(3), pp. 361-382. doi: 10.1080/15374416.2015.1110823.

McLaughlin, K. A. et al. (2019) 'Mechanisms linking childhood adversity with psychopathology: Learning as an intervention target', Behaviour Research and Therapy. Elsevier, 118(March), pp. 101109. doi: 10.1016/j.brat.2019.04.008.

Mclaughlin, K. A. and Sheridan, M. A. (2016) 'Beyond Cumulative Risk $\square$ : A Dimensional Approach to 
Childhood Adversity'. doi: 10.1177/0963721416655883.

McLaughlin, K. A., Sheridan, M. A. and Lambert, H. K. (2014) 'Childhood adversity and neural development: deprivation and threat as distinct dimensions of early experience.', Neuroscience and biobehavioral reviews. Elsevier Ltd, 47, pp. 578-91. doi: 10.1016/j.neubiorev.2014.10.012.

Mclaughlin, K. A., Sheridan, M. A. and Nelson, C. A. (2017) 'Neglect as a Violation of SpeciesExpectant Experience $\square$ : Neurodevelopmental Consequences', Biological Psychiatry. Elsevier Inc., 82(7), pp. 462-471. doi: 10.1016/j.biopsych.2017.02.1096.

Miller, A. B. et al. (2016) 'Dimensions of Deprivation and Threat, Psychopathology, and Potential Mediators: A Multi-Year Longitudinal Analysis', Journal of abnormal psychology, 127(2), pp. 160-170. doi: 10.1002/cncr.27633.Percutaneous.

Miller, L. E. (2015) 'Perceived Threat in Childhood: A Review of Research and Implications for Children Living in Violent Households', Trauma, Violence, and Abuse, 16(2), pp. 153-168. doi: $10.1177 / 1524838013517563$.

Noble, K. G., McCandliss, B. D. and Farah, M. J. (2007) 'Socioeconomic gradients predict individual differences in neurocognitive abilities', Developmental Science, 10(4), pp. 464-480. doi: 10.1111/j.14677687.2007.00600.x.

Platt, J. M. et al. (2018) 'Targeted Estimation of the Relationship between Childhood Adversity and Fluid Intelligence in a US Population Sample of Adolescents', American Journal of Epidemiology, 187(7), pp. 1456-1466. doi: 10.1093/aje/kwy006.

Pollak, S. D. et al. (2000) 'Recognizing emotion in faces: developmental effects of child abuse and neglect.', Developmental psychology, 36(5), pp. 679-688. doi: 10.1037/0012-1649.36.5.679.

Pollak, S. D. and Kistler, D. J. (2002) 'Early experience is associated with the development of categorical representations for facial expressions of emotion', Proceedings of the National Academy of Sciences, 99(13), pp. 9072-9076. doi: 10.1073/pnas.142165999.

Pollak, S. D. and Sinha, P. (2002) 'Effects of early experience on children's recognition of facial displays of emotion.', Developmental psychology, 38(5), pp. 784-791. doi: 10.1037/0012-1649.38.5.784.

Pollak, S. D. and Tolley-Schell, S. A. (2003) 'Selective attention to facial emotion in physically abused children’, Journal of Abnormal Psychology, pp. 323-338. doi: 10.1037/0021-843X.112.3.323.

Reinholdt-Dunne, M. L. et al. (2012) 'Effects of Age and Anxiety on Processing Threat Cues in Healthy Children', Journal of Experimental Psychopathology, 3(1), pp. 30-41. doi: 10.5127/jep.019611.

Salum, G. A. et al. (2014) 'High risk cohort study for psychiatric disorders in childhood: rationale , design , methods and preliminary results', Int. J. Methods Psychiatr. Res., (March). doi: 10.1002/mpr.

Salum, G. A. et al. (2016) 'Measuring child maltreatment using multi-informant survey data: a higherorder confirmatory factor analysis', Trends in Psychiatry and Psychotherapy, 38(1), pp. 23-32. doi: 10.1590/2237-6089-2015-0036.

Shackman, J. E. and Pollak, S. D. (2014) 'Impact of physical maltreatment on the regulation of negative affect and aggression', Development and Psychopathology, 26(4), pp. 1021-1033. doi: 10.1017/S0954579414000546.

Sheridan, M. et al. (2017) 'Dimensions of childhood adversity have distinct associations with neural 
systems underlying executive functioning', Development and Psychopathology, 29(5), pp. 1777-1794. doi: $10.1017 /$ S0954579417001390.

Sheridan, M. A. and Mclaughlin, K. A. (2014) 'Dimensions of early experience and neural development $\square$ : deprivation and threat', Trends in Cognitive Sciences. Elsevier Ltd, 18(11), pp. 580-585. doi: 10.1016/j.tics.2014.09.001.

Toplak, M. E. and Tannock, R. (2005) 'Tapping and Anticipation Performance in Attention Deficit Hyperactivity Disorder', Perceptual and Motor Skills, 100(3), pp. 659-675. doi: 10.2466/pms.100.3.659675.

Vandierendonck, A. et al. (2004) 'Working memory components of the Corsi blocks task', British Journal of Psychology, 95(1), pp. 57-79. doi: 10.1348/000712604322779460.

Viola, T. W. et al. (2016) 'The influence of geographical and economic factors in estimates of childhood abuse and neglect using the Childhood Trauma Questionnaire: A worldwide meta-regression analysis', Child Abuse and Neglect. Elsevier Ltd, 51(305141), pp. 1-11. doi: 10.1016/j.chiabu.2015.11.019.

Wechsler, D. (2002) WISC-III: Escala de Inteligência Wechsler para Crianças: Manual [Wechsler Intelligence Scale for Children-Third Edition]. São Paulo: Casa do Psicólogo.

Weissman, D. G. et al. (2019) 'Difficulties with emotion regulation as a transdiagnostic mechanism linking child maltreatment with the emergence of psychopathology', Development and Psychopathology, (April), pp. 1-17. doi: 10.1017/s0954579419000348.

Weissman, M. M. et al. (2000) 'Brief Screening for Family Psychiatric History', Archives of General Psychiatry, 57. 
bioRxiv preprint doi: https://doi org/10.1101/2020.02 09 940858; this version posted February 10, 2020. The copyright holder for this preprint (which was not certified by peer review) is the author/funder, who has granted bioRxiv a license to display the preprint in perpetuity. It is made available under aCC-BY-NC-ND 4.0 International license.

Table 1 - Sample description

Sex: male

Baseline

3-year follow-up

Site: São Paulo

$\begin{array}{lll}\mathbf{N} & \text { \% } & \text { Valid } \\ 1375 & 54.8 & 2511\end{array}$

Age (years)

$1256 \quad 50 \quad 251$

Family income (BRL)

\begin{tabular}{llllllll}
\hline Mean (sd) & Min & Max & Valid N & Mean (sd) & Min & Max & Valid N \\
\hline $10.2(1.9)$ & 5.83 & 14.37 & 2511 & $13.5(1.9)$ & 9.2 & 17.87 & 2010 \\
$757.6(536.6)$ & 29.94 & 4910.18 & 2110 & $783.8(656.8)$ & 21.65 & 8658.01 & 1679 \\
$17.2(16.1)$ & 0 & 101 & 2511 & $14.6(15.0)$ & 0 & 90 & 2010
\end{tabular}

Working Memory

Corsi block (backward)

$4.8(2.1) \quad 0 \quad 14$

Digit span (backward) 3.5 (1.6)

$0 \quad 12$

142223

$5.6(2.5)$

0

13

1880

Inhibitory Control

$\begin{array}{rr}\text { CCT \% Correct Inhibitions } & 0.6(0.2) \\ \text { Go/No-Go: Comission } & 0.3(0.2)\end{array}$

0
0

2249

$4.1(2.0)$

0

13

1880

Temporal Processing

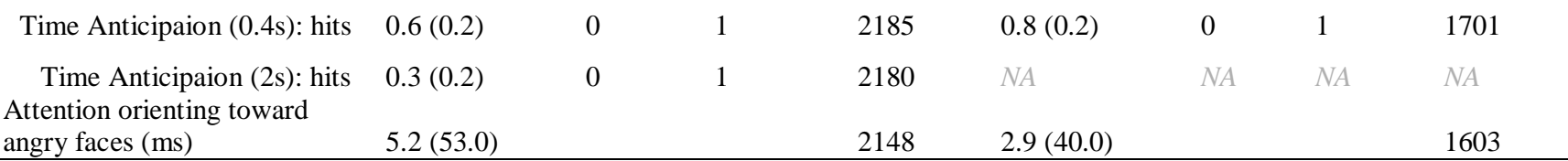

Note: crude scores for psychopathology, executive function tasks, and attention orienting toward angry faces are presented in order to inform about the variables' characteristics on the sample. 
bioRxiv preprint doi: https://doi org/10.1101/2020.02 09 940858; this version posted February $10,2020$. The copyright holder for this preprint (which was not certified by peer review) is the author/funder, who has granted bioRxiv a license to display the preprint in perpetuity. It is made available under aCC-BY-NC-ND 4.0 International license.

Table 2 - Factor loadings of the Threat and Deprivation Models at baseline and follow-up

\begin{tabular}{|c|c|c|c|c|c|c|c|c|}
\hline & \multicolumn{4}{|c|}{ Baseline } & \multicolumn{4}{|c|}{ Follow-up } \\
\hline & Estimate & S.E. & Est./S.E. & $p$-value & Estimate & S.E. & Est./S.E. & $p$-value \\
\hline \multicolumn{9}{|l|}{ Threat } \\
\hline Bullying exposure & 0.458 & 0.033 & 13.687 & $<0.001$ & 0.436 & 0.043 & 10.090 & $<0.001$ \\
\hline DAWBA: Physical abuse & 0.838 & 0.035 & 23.741 & $<0.001$ & 0.848 & 0.042 & 19.987 & $<0.001$ \\
\hline Physical abuse & 0.654 & 0.035 & 18.630 & $<0.001$ & 0.634 & 0.047 & 13.539 & $<0.001$ \\
\hline Emotional abuse & 0.532 & 0.029 & 18.263 & $<0.001$ & 0.619 & 0.036 & 17.207 & $<0.001$ \\
\hline DAWBA: Sexual abuse & 0.555 & 0.079 & 7.044 & $<0.001$ & - & - & - & - \\
\hline Sexual abuse & 0.576 & 0.062 & 9.293 & $<0.001$ & - & - & - & - \\
\hline Sexual abuse (combined) & - & - & - & - & 0.363 & 0.079 & 4.624 & $<0.001$ \\
\hline DAWBA: Attack or threat & 0.532 & 0.049 & 10.803 & $<0.001$ & 0.544 & 0.054 & 10.106 & $<0.001$ \\
\hline DAWBA: Domestic violence witnessing & 0.682 & 0.037 & 18.452 & $<0.001$ & 0.736 & 0.043 & 17.038 & $<0.001$ \\
\hline DAWBA: Attack witnessing & 0.690 & 0.042 & 16.300 & $<0.001$ & 0.740 & 0.049 & 15.002 & $<0.001$ \\
\hline \multicolumn{9}{|l|}{ Deprivation } \\
\hline Mother's educational level & 0.355 & 0.030 & 11.835 & $<0.001$ & 0.411 & 0.058 & 7.072 & $<0.001$ \\
\hline ABEP 2009: Stratified Score & 0.641 & 0.035 & 18.129 & $<0.001$ & 0.576 & 0.077 & 7.501 & $<0.001$ \\
\hline Father status & 0.406 & 0.041 & 9.821 & $<0.001$ & 0.235 & 0.060 & 3.881 & $<0.001$ \\
\hline Neglect & 0.621 & 0.038 & 16.148 & $<0.001$ & 0.465 & 0.071 & 6.527 & $<0.001$ \\
\hline Family income & 0.756 & 0.039 & 19.427 & $<0.001$ & 0.842 & 0.108 & 7.775 & $<0.001$ \\
\hline
\end{tabular}

Model fit baseline: $\mathrm{CFI}=0.942$, TLI= 0.928, RMSEA= 0.036; Model fit follow-up: $\mathrm{CFI}=0.923$, TLI= 0.903, RMSEA=0.037 
bioRxiv preprint doi: https://doi.org/10.1101/2020.02.09.940858; this version posted February 10,2020 . The copyright holder for this preprint (which was not certified by peer review) is the author/funder, who has granted bioRxiv a license to display the preprint in perpetuity. It is made available under aCC-BY-NC-ND 4.0 International license.

Table 3 - Cross-lagged Panel Models results

\begin{tabular}{|c|c|c|c|c|c|c|}
\hline \multicolumn{7}{|l|}{ Cross-sectional } \\
\hline & \multicolumn{3}{|c|}{ Baseline } & \multicolumn{3}{|c|}{ Follow-up } \\
\hline & $\beta$ & p value & CI 95\% & $\beta$ & p value & CI 95\% \\
\hline \multicolumn{7}{|l|}{ Threat } \\
\hline Psychopathology & 0.430 & $<0.001$ & $0.398,0.462$ & 0.349 & $<0.001$ & $0.311,0.388$ \\
\hline Executive Function & -0.086 & $<0.001$ & $-0.125,-0.046$ & 0.014 & 0.532 & $-0.031,0.060$ \\
\hline Attention Bias & 0.033 & 0.125 & $-0.009,0.075$ & 0.042 & 0.092 & $-0.007,0.091$ \\
\hline \multicolumn{7}{|l|}{ Deprivation } \\
\hline Psychopathology & 0.160 & $<0.001$ & $0.122,0.198$ & 0.058 & 0.010 & $0.014,0.101$ \\
\hline Executive Function & -0.155 & $<0.001$ & $-0.194,-0.116$ & -0.061 & 0.008 & $-0.106,-0.016$ \\
\hline Attention Bias & -0.027 & 0.210 & $-0.069,0.015$ & -0.057 & 0.024 & $-0.106,-0.008$ \\
\hline \multicolumn{7}{|c|}{ Longitudinal associations } \\
\hline & \multicolumn{3}{|c|}{ Adversity $\rightarrow$ Outcome } & \multicolumn{3}{|c|}{ Outcome $\rightarrow$ Adversity } \\
\hline & $\beta$ & p value & CI $95 \%$ & $\beta$ & p value & CI 95\% \\
\hline Psychopathology & & & & - & & \\
\hline Threat & 0.121 & $<0.001$ & $0.076,0.167$ & 0.123 & $<0.001$ & $0.078,0.168$ \\
\hline Deprivation & 0.064 & 0.003 & $0.022,0.107$ & 0.038 & 0.047 & $0.000,0.076$ \\
\hline \multicolumn{7}{|l|}{ Executive Function } \\
\hline Threat & -0.031 & 0.160 & $-0.074,0.012$ & -0.031 & 0.150 & $-0.074,0.012$ \\
\hline Deprivation & -0.041 & 0.069 & $-0.085,0.003$ & -0.056 & 0.002 & $-0.091,-0.021$ \\
\hline \multicolumn{7}{|l|}{ Attention bias } \\
\hline Threat & -0.044 & 0.096 & $-0.096,0.008$ & -0.010 & 0.650 & $-0.055,0.034$ \\
\hline Deprivation & 0.013 & 0.619 & $-0.039,0.066$ & -0.030 & 0.109 & $-0.067,0.007$ \\
\hline \multicolumn{7}{|l|}{ Autoregressive } \\
\hline & \multicolumn{3}{|c|}{ Autoregressive } & & & \\
\hline & $\beta$ & p value & CC $95 \%$ & & & \\
\hline Psychopathology & 0.336 & $<0.001$ & $0.295,0.378$ & & & \\
\hline Threat & 0.280 & $<0.001$ & $0.234,0.326$ & & & \\
\hline Deprivation & 0.638 & $<0.001$ & $0.609,0.667$ & & & \\
\hline Executive Function & 0.435 & $<0.001$ & $0.398,0.473$ & & & \\
\hline Threat & 0.330 & $<0.001$ & $0.288,0.371$ & & & \\
\hline Deprivation & 0.631 & $<0.001$ & $0.601,0.660$ & & & \\
\hline Attention bias & 0.064 & 0.025 & $0.008,0.120$ & & & \\
\hline Threat & 0.331 & $<0.001$ & $0.289,0.373$ & & & \\
\hline Deprivation & 0.637 & $<0.001$ & $0.608,0.666$ & & & \\
\hline
\end{tabular}

Outcome: either psychopathology, executive function, or attention orienting toward angry faces

Adversity: either Threat or Deprivation

Note: Threat at baseline did not predict Deprivation at Follow-up $(\beta=-0.036, p=0.115, \mathrm{CI} 95 \%-0.080$ to 0.009$)$, but deprivation at baseline predicted modestly lower levels of threat at follow-up $((\beta=-0.053$, $\mathrm{p}=0.008$, CI95\% -0.093 to -0.014 ). 
bioRxiv preprint doi: https://doi.org/10.1101/2020.02.09.940858; this version posted February 10,2020 . The copyright holder for this preprint (which was not certified by peer review) is the author/funder, who has granted bioRxiv a license to display the preprint in perpetuity. It is made available under aCC-BY-NC-ND 4.0 International license.

Table 4 - Post hoc Cross-lagged Panel Models results

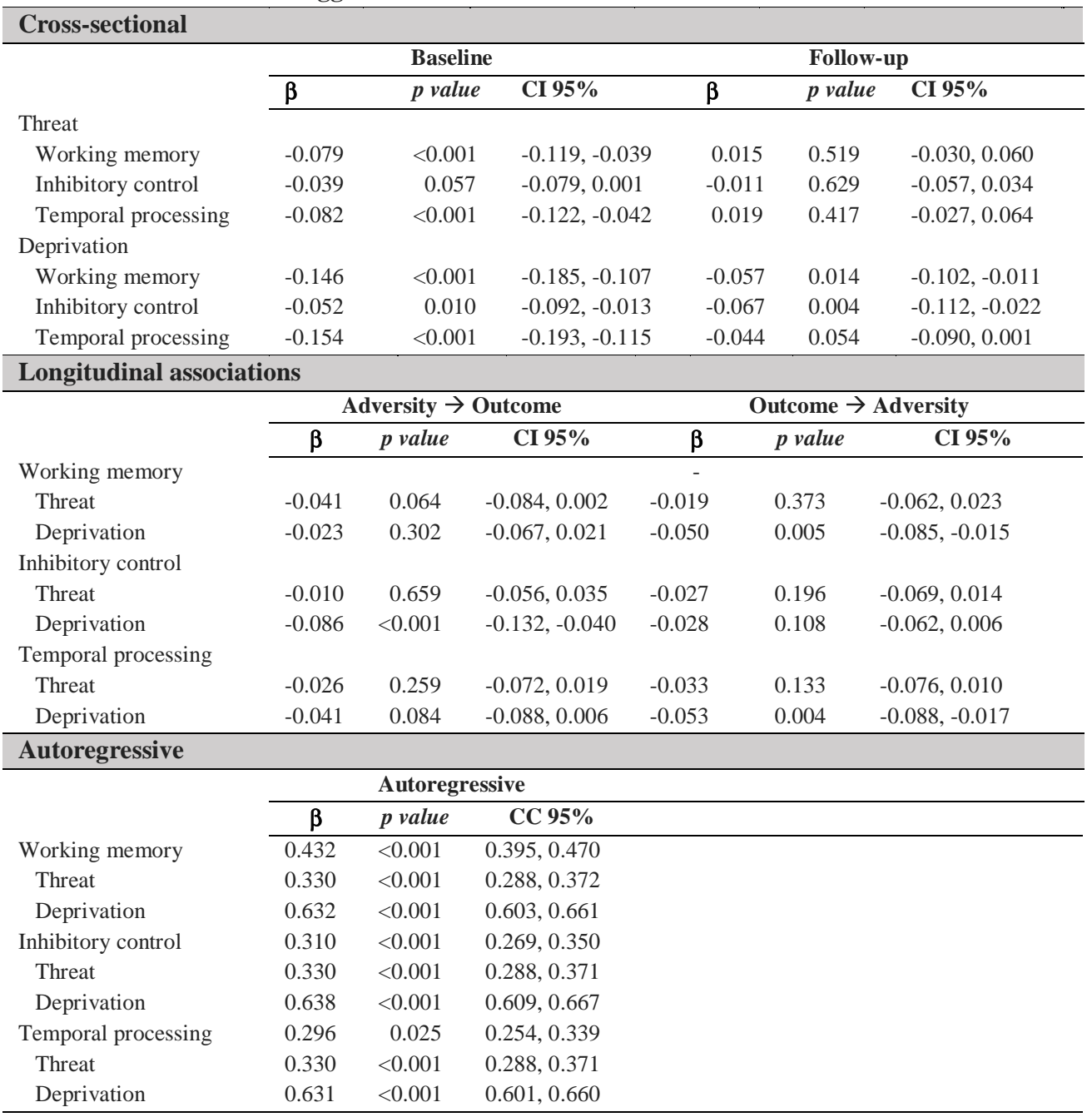

Outcome: either working memory, inhibitory control, and temporal processing

Adversity: either Threat or Deprivation 
Figure 1 - Cross Lagged Panel Models showing cross-sectional and longitudinal associations between general psychopathology, executive function, attention orienting toward angry faces and threat and deprivation in baseline and 3-year follow-up assessments

\section{Panel A - General psychopathology}

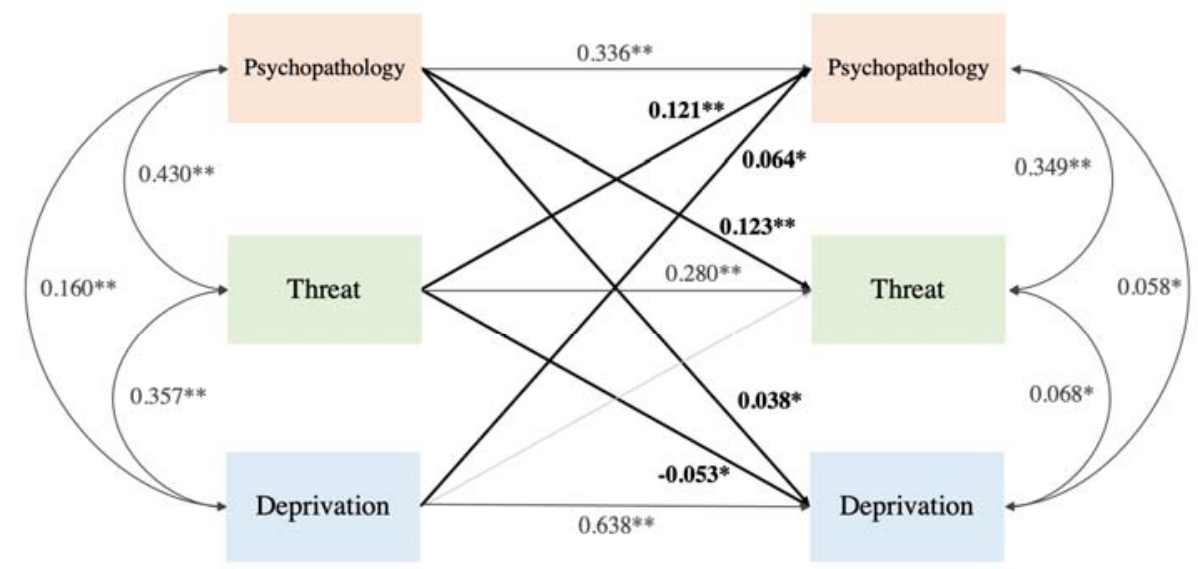

${ }^{*} \mathrm{p}=<0.05 .{ }^{* *} \mathrm{p}<0.001$

\section{Panel B - Executive Function}

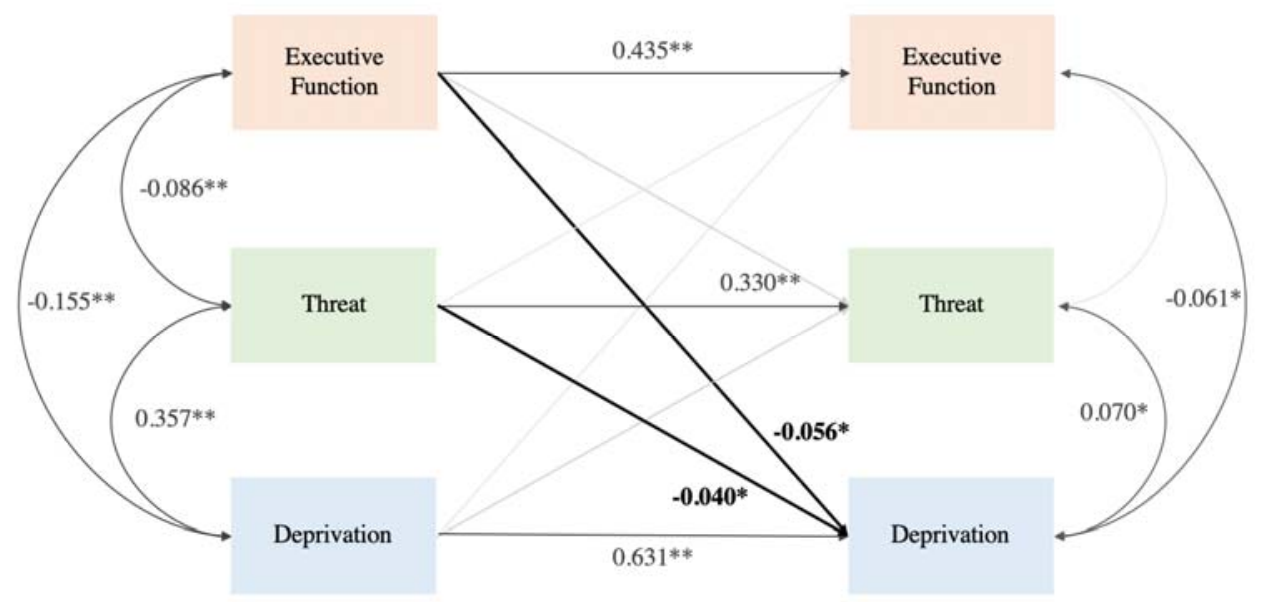

${ }^{*} \mathrm{p}=<0.05 .{ }^{* *} \mathrm{p}<0.001$ 
bioRxiv preprint doi: https://doi.org/10.1101/2020.02.09.940858; this version posted February 10,2020 . The copyright holder for this preprint (which was not certified by peer review) is the author/funder, who has granted bioRxiv a license to display the preprint in perpetuity. It is made available under aCC-BY-NC-ND 4.0 International license.

\section{Panel C - Attention orienting toward angry faces}

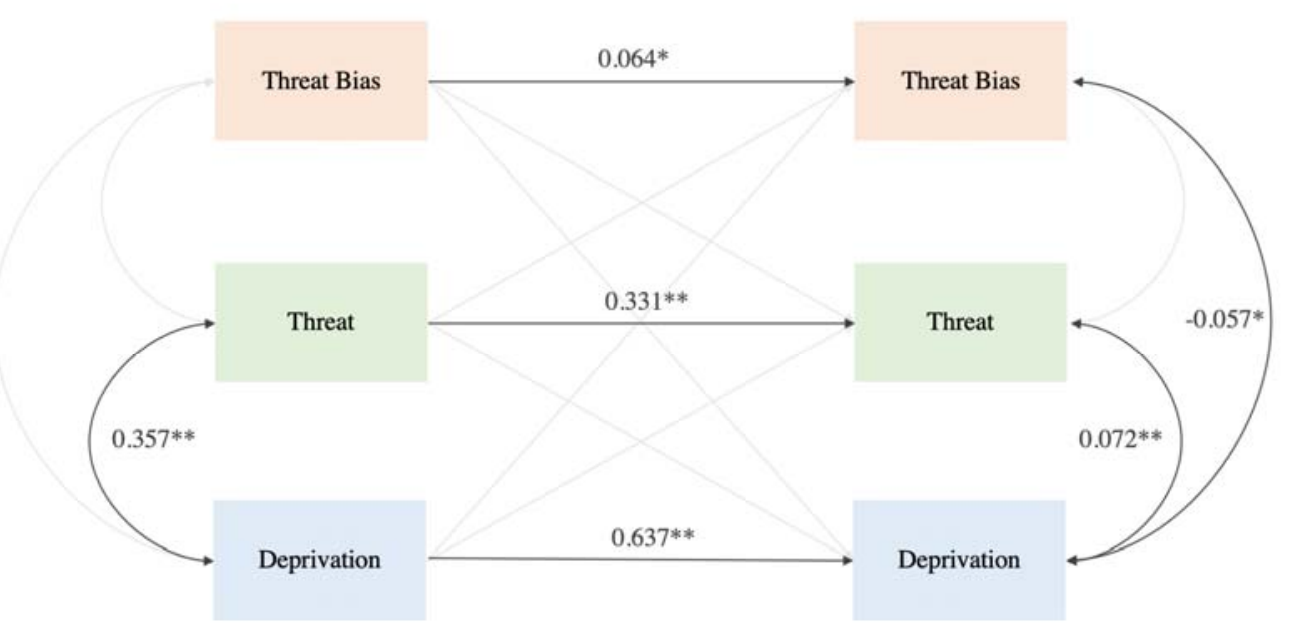

${ }^{*} \mathrm{p}=<0.05 .{ }^{* *} \mathrm{p}<0.001$. 
bioRxiv preprint doi: https://doi.org/10.1101/2020.02.09.940858; this version posted February 10, 2020. The copyright holder for this preprint (which was not certified by peer review) is the author/funder, who has granted bioRxiv a license to display the preprint in perpetuity. It is made available under aCC-BY-NC-ND 4.0 International license.

\section{Supplemental Material}

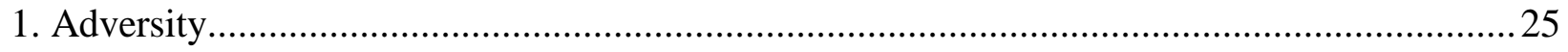

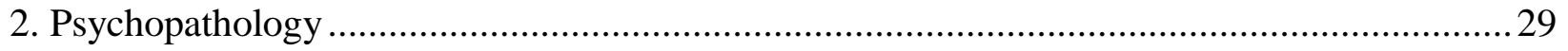

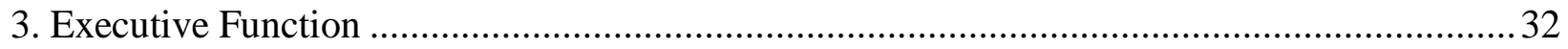




\section{Adversity}

Threat and deprivation variables were selected according to documented theoretical models in order to encompass both dimensions of childhood adversity. Selected variables, their label and ranges are described below (Supplemental Table S1), as well as descriptive data for each selected variable (Supplemental Table S2). At baseline, all exposure questions were asked considering the lifetime time range, while at follow-up exposure was assessed and considered positive only if it happened over the past three-year time range.

Confirmatory factor analysis, using the full maximum likelihood to deal with missing data, were conducted using baseline and follow-up data. The threat and deprivation model at baseline was available for 2511 participants, and at follow up 2010 participants (Supplemental Figure S1). 


\begin{tabular}{|c|c|c|}
\hline \multicolumn{3}{|l|}{ Threat } \\
\hline Bullying exposure & Has the child ever been bullied in his life? & $\begin{array}{l}\text { No } \\
\text { Ye }\end{array}$ \\
\hline DAWBA: Physical abuse & $\begin{array}{l}\text { Has the child ever suffered physical violence } \\
\text { (maltreatment) that he/she remembers? }\end{array}$ & $\begin{array}{l}\text { No } \\
\text { Yes }\end{array}$ \\
\hline Physical abuse & $\begin{array}{l}\text { Has your child been seriously picked up by an adult } \\
\text { (including yourself), to the point of leaving marks in } \\
\text { his body? }\end{array}$ & $\begin{array}{l}\text { Never } \\
\text { Yes, once or twice } \\
\text { Yes, from time to time } \\
\text { Yes, often happen }\end{array}$ \\
\hline Emotional abuse & $\begin{array}{l}\text { Has your child ever been cursed by some adult, with } \\
\text { words like 'ass', 'idiot', 'stupid', or being yelled that } \\
\text { you were no good? }\end{array}$ & $\begin{array}{l}\text { Never } \\
\text { Yes, once or twice } \\
\text { Yes, from time to time } \\
\text { Yes, often happen }\end{array}$ \\
\hline DAWBA: Sexual abuse & Has the child ever been exposed to sexual abuse? & $\begin{array}{l}\text { No } \\
\text { Yes }\end{array}$ \\
\hline Sexual abuse & $\begin{array}{l}\text { Has anybody ever done sexual things with your } \\
\text { child, or have threatened your child if he/she didn't } \\
\text { do sexual things? }\end{array}$ & $\begin{array}{l}\text { Never } \\
\text { Yes, once or twice } \\
\text { Yes, from time to time } \\
\text { Yes, often happen }\end{array}$ \\
\hline DAWBA: Attack or threat & Has the child ever been attacked or threatened? & $\begin{array}{l}\text { No } \\
\text { Yes }\end{array}$ \\
\hline DAWBA: Domestic violence witnessing & $\begin{array}{l}\text { Has the child ever witnessed serious domestic } \\
\text { violence? }\end{array}$ & $\begin{array}{l}\text { No } \\
\text { Yes }\end{array}$ \\
\hline DAWBA: Attack witnessing & $\begin{array}{l}\text { Has the child ever seen a family member, or friend } \\
\text { being seriously attacked, or threatened? }\end{array}$ & $\begin{array}{l}\text { No } \\
\text { Yes }\end{array}$ \\
\hline \multicolumn{3}{|l|}{ Deprivation } \\
\hline Mother's educational level & Mother's educational level & $\begin{array}{l}\text { Postgraduate } \\
\text { Graduate (complete) } \\
\text { Graduate (incomplete) } \\
\text { High School (complete) } \\
\text { High School (incomplete) } \\
\text { Middle School(complete) } \\
\text { Middle School(incomplete) } \\
\text { Without study }\end{array}$ \\
\hline ABEP 2009: Stratified Score & Socio economic class & $\begin{array}{l}\text { D/E (poorest) } \\
\text { C } \\
\text { A/B (wealthiest) }\end{array}$ \\
\hline Father status & $\begin{array}{l}\text { What is the current contact status of the child's } \\
\text { father? }\end{array}$ & $\begin{array}{l}\text { In contact } \\
\text { No-contact } \\
\text { Deceased } \\
\text { Unknown }\end{array}$ \\
\hline Neglect & $\begin{array}{l}\text { Has it ever happened to your child of not having } \\
\text { anything to eat and/or having to wear dirty or torn } \\
\text { clothes? }\end{array}$ & $\begin{array}{l}\text { Never } \\
\text { Yes, once or twice } \\
\text { Yes, from time to time } \\
\text { Yes, often happens }\end{array}$ \\
\hline Family income & What is the family total income? & Divided into quintiles \\
\hline
\end{tabular}


bioRxiv preprint doi: https://doi org/10.1101/2020.02 09 940858; this version posted February $10,2020$. The copyright holder for this preprint (which was not certified by peer review) is the author/funder, who has granted bioRxiv a license to display the preprint in perpetuity. It is made available under aCC-BY-NC-ND 4.0 International license.

Supplemental Table S2 - Threat and Deprivation variable frequency

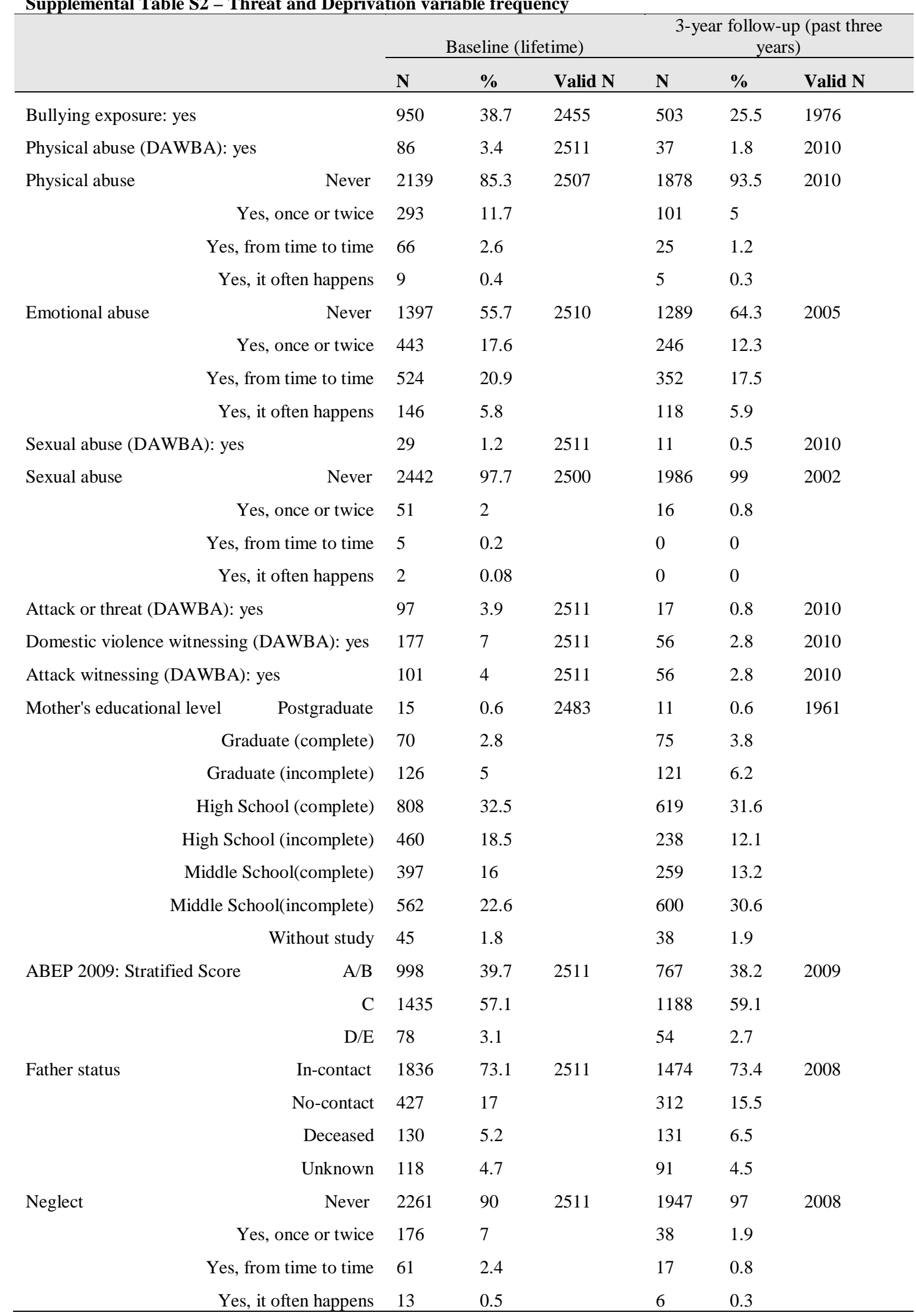


bioRxiv preprint doi: https://doi org/10.1101/2020.02 09 940858; this version posted February 10,2020 . The copyright holder for this preprint (which was not certified by peer review) is the author/funder, who has granted bioRxiv a license to display the preprint in perpetuity. It is made available under aCC-BY-NC-ND 4.0 International license.

\section{Supplemental Figure S1 - Threat and Deprivation model depiction at baseline and follow-up}
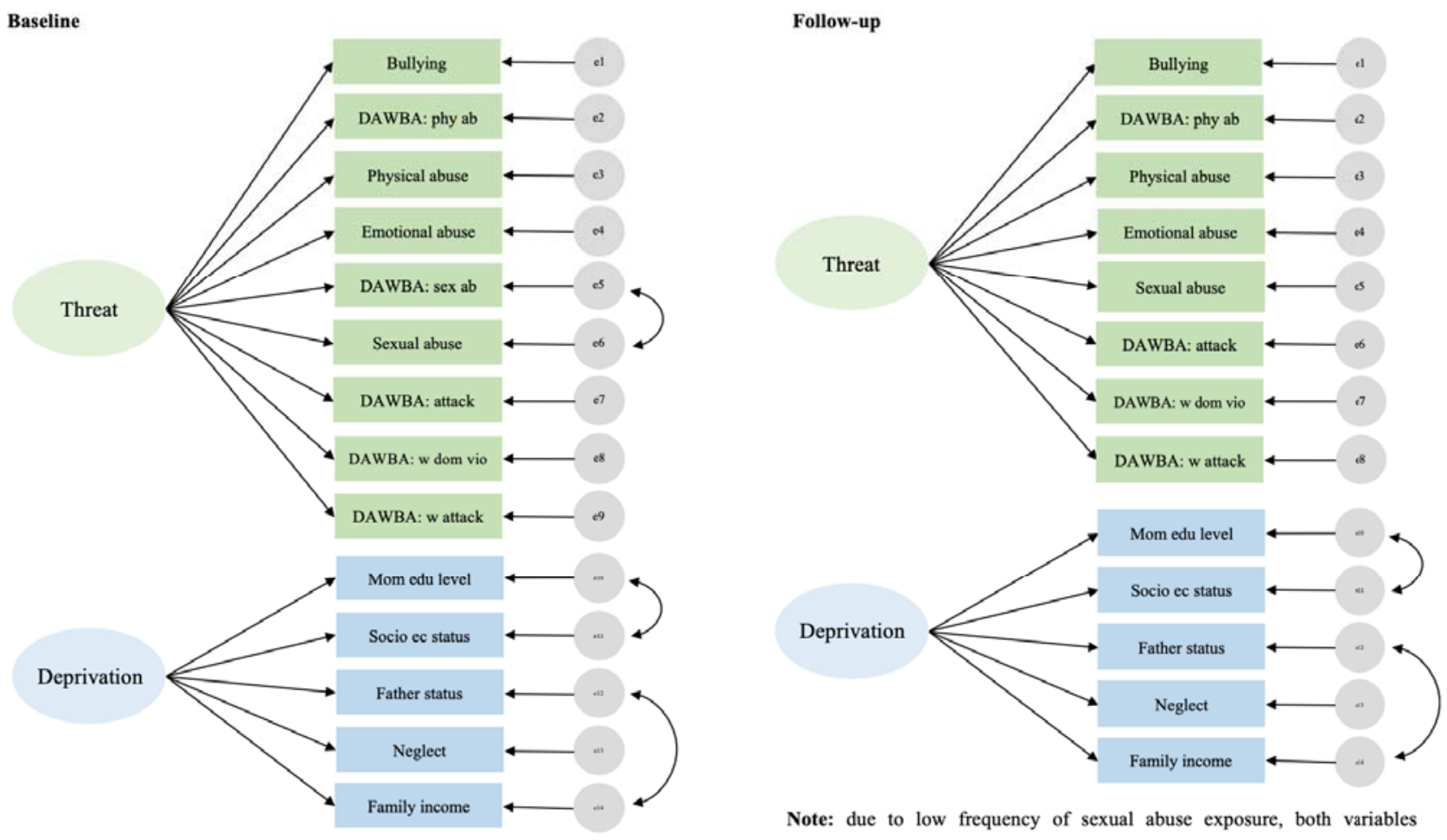

Note: due to low frequency of sexual abuse exposure, both variables informing about sexual abuse exposure were combined. 


\section{Psychopathology}

Confirmatory factor analysis, using the diagonally weighted least squares (DWLS) estimator, were conducted using CBCL baseline and follow-up data using a bifactor model in which all items are loaded in a general factor (the "p" factor) and residuals variance is captured by internalizing and externalizing domains as outlined by the CBCL scoring system. The psychopathology model at baseline was available for 2511 participants and showed adequate fit indexes (CFI= 0.984, TLI= 0.983, RMSEA= 0.020). The psychopathology model at follow up was available for 2010 participants and also showed adequate fit indexes $(\mathrm{CFI}=0.973$, TLI= 0.972, RMSEA=0.025). Factor loadings for baseline and followup data are found on Supplemental Table S3. 


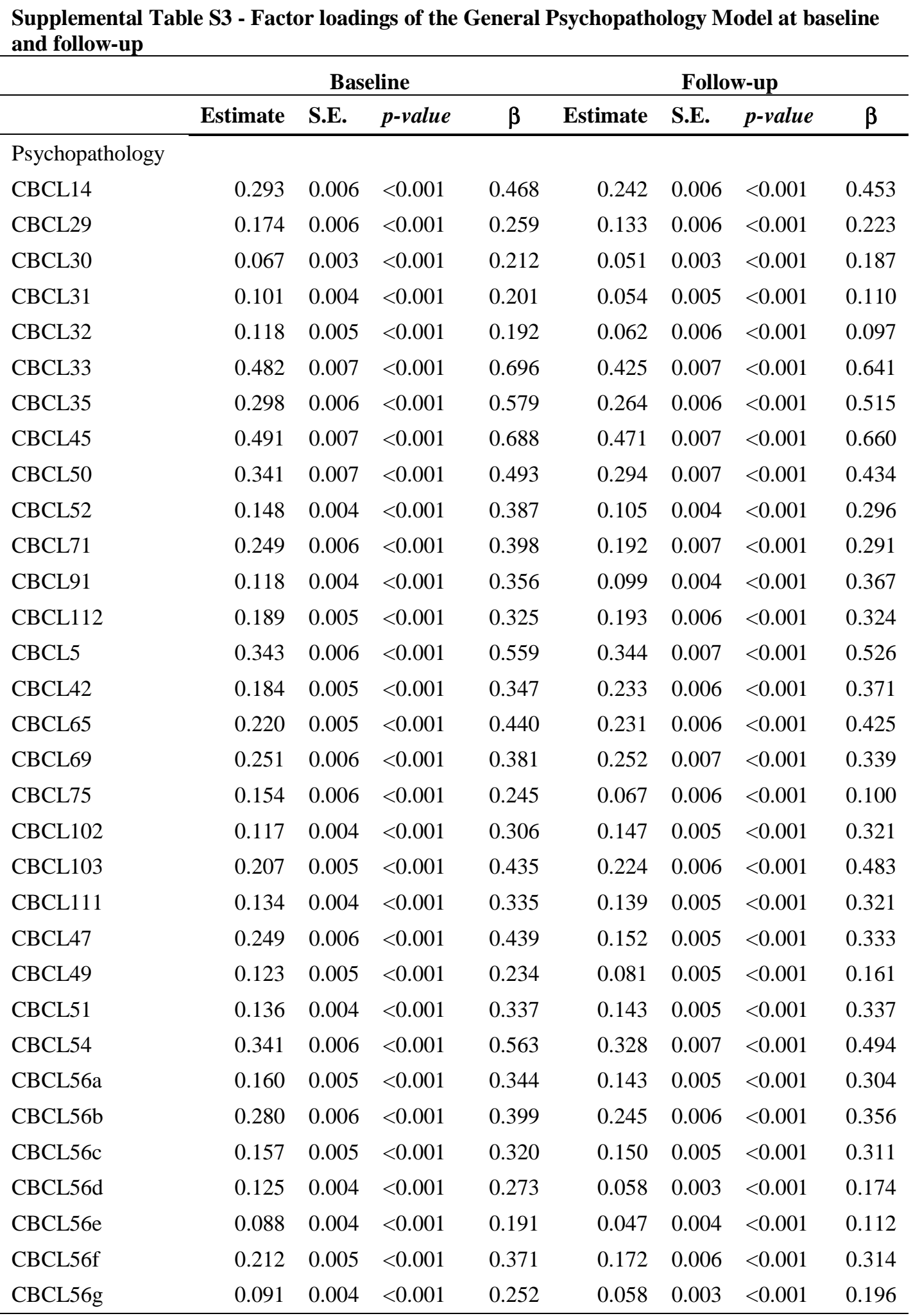

Table continues on next page 


\begin{tabular}{|c|c|c|c|c|c|c|c|c|}
\hline & \multicolumn{4}{|c|}{ Baseline } & \multicolumn{4}{|c|}{ Follow-up } \\
\hline & Estimate & S.E. & $p$-value & $\beta$ & Estimate & S.E. & p-value & $\beta$ \\
\hline CBCL2 & 0.017 & 0.002 & $<0.001$ & 0.098 & 0.063 & 0.004 & $<0.001$ & 0.199 \\
\hline CBCL26 & 0.273 & 0.006 & $<0.001$ & 0.467 & 0.249 & 0.006 & $<0.001$ & 0.448 \\
\hline CBCL28 & 0.312 & 0.006 & $<0.001$ & 0.517 & 0.367 & 0.007 & $<0.001$ & 0.588 \\
\hline CBCL39 & 0.061 & 0.003 & $<0.001$ & 0.206 & 0.087 & 0.004 & $<0.001$ & 0.239 \\
\hline CBCL43 & 0.213 & 0.006 & $<0.001$ & 0.366 & 0.245 & 0.007 & $<0.001$ & 0.451 \\
\hline CBCL63 & 0.249 & 0.006 & $<0.001$ & 0.378 & 0.262 & 0.007 & $<0.001$ & 0.374 \\
\hline CBCL67 & 0.040 & 0.002 & $<0.001$ & 0.171 & 0.052 & 0.003 & $<0.001$ & 0.212 \\
\hline CBCL72 & 0.064 & 0.003 & $<0.001$ & 0.246 & 0.022 & 0.002 & $<0.001$ & 0.130 \\
\hline CBCL73 & 0.028 & 0.002 & $<0.001$ & 0.155 & 0.003 & 0.001 & $<0.001$ & 0.032 \\
\hline CBCL81 & 0.036 & 0.003 & $<0.001$ & 0.137 & 0.021 & 0.002 & $<0.001$ & 0.117 \\
\hline CBCL82 & 0.033 & 0.002 & $<0.001$ & 0.141 & 0.006 & 0.002 & $<0.001$ & 0.042 \\
\hline CBCL90 & 0.265 & 0.006 & $<0.001$ & 0.469 & 0.325 & 0.007 & $<0.001$ & 0.511 \\
\hline CBCL96 & 0.056 & 0.003 & $<0.001$ & 0.213 & 0.043 & 0.002 & $<0.001$ & 0.181 \\
\hline CBCL99 & 0.008 & 0.001 & $<0.001$ & 0.065 & 0.015 & 0.002 & $<0.001$ & 0.079 \\
\hline CBCL101 & 0.074 & 0.003 & $<0.001$ & 0.258 & 0.114 & 0.005 & $<0.001$ & 0.283 \\
\hline CBCL105 & 0.009 & 0.001 & $<0.001$ & 0.073 & 0.011 & 0.002 & $<0.001$ & 0.074 \\
\hline CBCL106 & 0.027 & 0.002 & $<0.001$ & 0.160 & 0.007 & 0.001 & $<0.001$ & 0.062 \\
\hline CBCL3 & 0.456 & 0.007 & $<0.001$ & 0.585 & 0.404 & 0.007 & $<0.001$ & 0.534 \\
\hline CBCL16 & 0.069 & 0.003 & $<0.001$ & 0.236 & 0.049 & 0.003 & $<0.001$ & 0.233 \\
\hline CBCL19 & 0.481 & 0.007 & $<0.001$ & 0.661 & 0.384 & 0.007 & $<0.001$ & 0.579 \\
\hline CBCL20 & 0.220 & 0.006 & $<0.001$ & 0.402 & 0.149 & 0.005 & $<0.001$ & 0.355 \\
\hline CBCL21 & 0.181 & 0.005 & $<0.001$ & 0.387 & 0.117 & 0.005 & $<0.001$ & 0.317 \\
\hline CBCL22 & 0.346 & 0.006 & $<0.001$ & 0.522 & 0.395 & 0.007 & $<0.001$ & 0.622 \\
\hline CBCL23 & 0.214 & 0.006 & $<0.001$ & 0.372 & 0.230 & 0.007 & $<0.001$ & 0.408 \\
\hline CBCL37 & 0.182 & 0.005 & $<0.001$ & 0.383 & 0.140 & 0.005 & $<0.001$ & 0.350 \\
\hline CBCL57 & 0.083 & 0.004 & $<0.001$ & 0.258 & 0.078 & 0.004 & $<0.001$ & 0.288 \\
\hline CBCL68 & 0.338 & 0.006 & $<0.001$ & 0.533 & 0.347 & 0.007 & $<0.001$ & 0.565 \\
\hline CBCL86 & 0.520 & 0.007 & $<0.001$ & 0.707 & 0.523 & 0.007 & $<0.001$ & 0.729 \\
\hline CBCL87 & 0.513 & 0.007 & $<0.001$ & 0.770 & 0.497 & 0.008 & $<0.001$ & 0.717 \\
\hline CBCL88 & 0.574 & 0.007 & $<0.001$ & 0.773 & 0.552 & 0.008 & $<0.001$ & 0.749 \\
\hline CBCL89 & 0.431 & 0.007 & $<0.001$ & 0.677 & 0.397 & 0.007 & $<0.001$ & 0.605 \\
\hline CBCL94 & 0.274 & 0.006 & $<0.001$ & 0.447 & 0.230 & 0.007 & $<0.001$ & 0.369 \\
\hline CBCL95 & 0.479 & 0.007 & $<0.001$ & 0.681 & 0.528 & 0.008 & $<0.001$ & 0.743 \\
\hline CBCL97 & 0.063 & 0.003 & $<0.001$ & 0.250 & 0.049 & 0.003 & $<0.001$ & 0.229 \\
\hline CBCL104 & 0.301 & 0.006 & $<0.001$ & 0.449 & 0.300 & 0.007 & $<0.001$ & 0.478 \\
\hline
\end{tabular}




\section{Executive Function}

Six executive function tasks were used as measures of working memory, inhibitory control and temporal processing. Missing data differs from one task to another over both time points due to assessment being performed over four sessions at baseline.

Executive function was derived from a second order model encompassing working memory inhibitory control and temporal processing at baseline and follow up. Due to the differing variability of the executive function tasks, scores were standardized regressing using General Additive Models regressing out effects of age and gender on the task parameters. At baseline, each executive function dimension was encompassed by two cognitive tasks, and at follow-up, due to the absence of one of the tasks data, the temporal processing dimension was encompassed by one task (Supplemental Figure S2).

Confirmatory factor analysis, using the full maximum likelihood to deal with missing data, were conducted using baseline and follow-up data. The executive function model at baseline was available for 2396 participants, and the follow up model for 1880 participants. Fit indexes and factor loadings are shown on Supplemental Table S4. 
Supplemental Table S4 - Standardized factor loadings of the baseline Executive Function Model

\begin{tabular}{rrrrrrrr}
\hline & \multicolumn{3}{c}{ Baseline } & \multicolumn{3}{c}{ Follow-up } \\
\cline { 2 - 7 } & $\lambda$ & S.E. & $\boldsymbol{p}$-value & $\lambda$ & S.E. & $\boldsymbol{p}$-value \\
\hline Working Memory (WM) & & & & & & \\
Digit span (back) & 0.626 & 0.028 & $<0.001$ & 0.703 & 0.024 & $<0.001$ \\
Corsi blocks (back) & 0.669 & 0.029 & $<0.001$ & 0.787 & 0.025 & $<0.001$ \\
Inhibitory Control (IC) & & & & & & \\
CCT (\% Inhibitions, inverse) & 0.989 & 0.074 & $<0.001$ & 0.577 & 0.043 & $<0.001$ \\
GNG (\% Comission) & -0.401 & 0.035 & $<0.001$ & 0.471 & 0.038 & $<0.001$ \\
Temporal Processing (TP) & & & & & & \\
Hits (400ms) & 0.630 & 0.026 & $<0.001$ & 1.000 & 0.000 & $<0.001$ \\
Hits (2s) & 0.736 & 0.028 & $<0.001$ & - & - & - \\
Executive Function & & & & & & \\
& & & & & - & & \\
WM & 0.685 & 0.042 & $<0.001$ & 0.721 & 0.046 & $<0.001$ \\
IC & 0.462 & 0.046 & $<0.001$ & 0.652 & 0.053 & $<0.001$ \\
TP & 0.728 & 0.042 & $<0.001$ & 0.590 & 0.039 & $<0.001$
\end{tabular}

Model fit baseline: $\mathrm{CFI}=0.999$, TLI= 0.997, RMSEA= 0.011; Model fit follow-up: $\mathrm{CFI}=$ $1.000, \mathrm{TLI}=1.006, \mathrm{RMSEA}=0.000$ 
Supplemental Figure S2 -Executive Function Model baseline and follow=up

Baseline

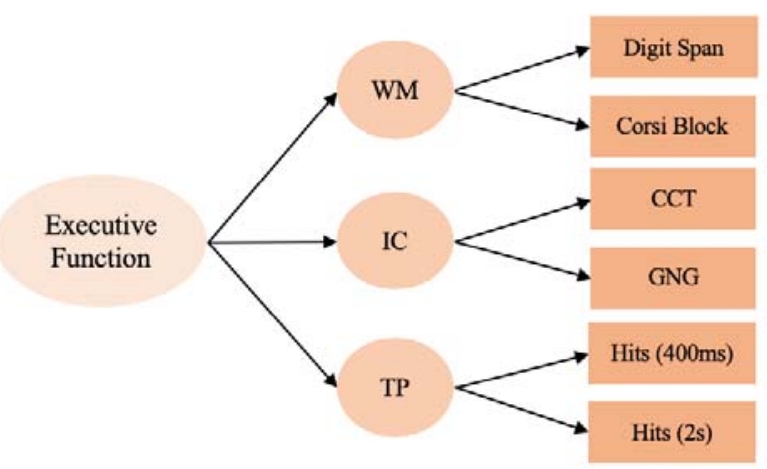

Follow-up

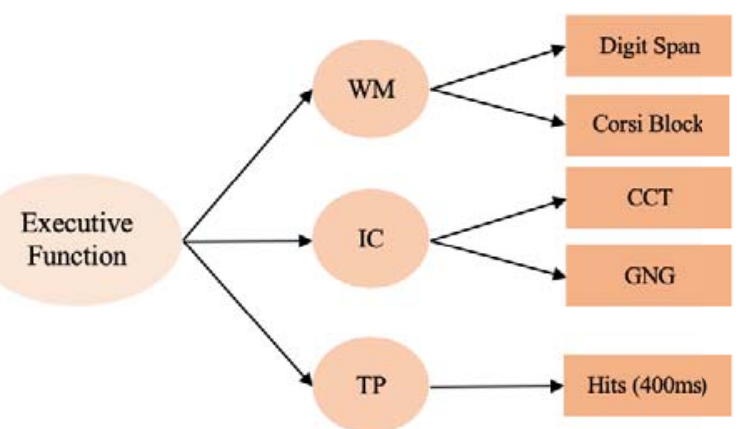

